Preference is given to letters commenting on contributions published recently in the JRSM. They should not exceed 300 words and should be typed double spaced

\section{Capacity and consent}

Dr Jackson and Dr Warner highlight worrying deficiencies in clinicians' judgments on capacity and consent to treatment (December $2002 J R S M^{1}$ ). Unfortunately, their summary may further confuse matters by stating that, ' $15 \%$ of all respondents wrongly believed that a competent adult could lawfully be treated against his or her will'. In fact, competent adults can be lawfully treated against their will, in certain clearly defined circumstances. The key omission here is the phrase, 'under common law' (which was included in the question posed to doctors). This was no doubt an oversight, but it draws attention to a related concernnamely, that doctors (and medical students) often seem to conflate judgments about capacity and the common law with judgments about mental disorder and the Mental Health Act, when discussing whether patients can be treated without their consent. In fact such judgments should be clearly distinct. Someone with a mental disorder who is detained under the Act may still meet the capacity criteria (and thereby be judged competent) to consent to, or refuse, certain medical treatments ${ }^{2}$. Contrariwise, an individual without a mental disorder may fail to meet the capacity threshold, and be deemed incompetent.

Jackson and Warner also found that medical students were very poor at identifying the criteria for capacity, with only $15 \%$ doing so correctly. That students are misinformed about issues of medical ethics and law is not surprising. In a recent teaching session, a senior doctor insisted to our group that in England an adult (such as a spouse) could consent to medical treatment on behalf of another adult. Until the teachers are correctly informed about these important issues, what hope for their students?

\section{Bruno James Rushforth}

Medical School, Manchester University, Manchester, UK

E-mail: b.j.rushforth@stud.man.ac.uk

\section{REFERENCES}

1 Jackson E, Warner J. How much do doctors know about consent and capacity? J R Soc Med 2002;95:601-3

2 Re C (Adult: Refusal of Treatment) 1. All England Reports 1994: 819

\section{Pooled waiting lists}

Mr Ramchandani and his colleagues report the attitudes of hospital consultants, general practitioners and patients to pooled waiting lists for cataract surgery (December 2002 $\left.J R S M^{1}\right)$. I think that this strategy could improve efficiency in
In the UK patients are traditionally admitted to gynaecology units under a named consultant. In essence, this means that NHS consultants 'work together in isolation'. By contrast, in Continental Europe referrals to gynaecology units tend to be 'generic'. Patients are the responsibility of the whole department, headed by a chief of staff. They are looked after by teams with an appropriate special interest, and the most suitable surgeon is internally allocated to each patient. This achieves uniformity of practice and equality of patient care. The patient turn-over is quick and there are no waiting lists for investigations.

This arrangement has other benefits. It should reduce the disparities that arise when inexperienced specialist registrars enter the system. In the European units I have visited, groups of consultants work together in the operating theatre or the clinic. This provides clinicians with the opportunity to monitor each other's performance, update techniques, and expand repertoires and to reciprocate teaching opportunities. This arrangement also facilitates audit and learning, and enhances patient safety. It truly is lifelong learning.

One of the arguments against the European structure is that UK consultants would not want to sacrifice their clinical autonomy and work under a 'chief of staff'. This argument is becoming less tenable. We are directly accountable to the clinical or medical director through appraisal and revalidation as part of our jobs plans. Besides, if our management is evidence based and 'best practice' it should be consistent with that of our colleagues. Therefore, I do not see loss of traditional autonomy as an important issue.

\section{Kevin Jones}

62 Stoke Road, Guildford, Surrey GU1 4HR, UK

E-mail: jnkevin@aol.com

\section{REFERENCE}

1 Ramchandani M, Mirza S, Sharma A, Kirkby G. Pooled cataract waiting lists: views of hospital consultants, general practitioners and patients. $J R$ Soc Med 2002;95:598-600

\section{Shaken baby syndrome}

With the December 2002 issue of the JRSM I received a colour brochure advertising the European Conference on Shaken Baby Syndrome, to be held in Edinburgh in May 2003. The chief sponsor is the National Center on Shaken Baby Syndrome, USA, but supporters include the RSM. Shaken baby syndrome (or shaken impact syndrome) is a hypothetical condition, albeit believed in by some with a religious passion. In the hurly-burly of full-time paediatric neurological practice I used to believe in it myself; however, within the past two years publications from several centres have critically questioned the assumptions underlying the 
concept and the diagnosis ${ }^{1-7}$. If the purpose of the conference is scientific enquiry and rational discourse, it is surprising that the authors of these publications are entirely absent from the list of invited speakers.

John B P Stephenson

Cruachan, Bowmore, Isle of Islay, PA43 7HR, UK

\section{REFERENCES}

1 Plunkett J. Fatal pediatric head injuries caused by short-distance falls. Am J Forensic Med Pathol 2001;22:1-12

2 Geddes JF, Hackshaw AK, Vowles GH, Nickols CD, Whitwell HL. Neuropathology of inflicted head injury in children. I. Patterns of brain damage. Brain 2001;124:1290-8

3 Clark BJ. Retinal hemorrhages: evidence of abuse or abuse of evidence? Am J Forensic Med Pathol 2001;22:415-16

4 Clark BJ, Adams GG, Luthert PJ. Retinal haemorrhages in infant head injury. Brain 2002;125:677-8

5 Uscinski R. Shaken baby syndrome: fundamental questions. $B r \mathrm{~J}$ Neurosurg 2002;16:217-19

6 Ommaya AK, Goldsmith W, Thibault L. Biomechanics and neuropathology of adult and paediatric head injury. Br J Neurosurg 2002;16:220-42

7 Vinchon M, Noizet O, Defoort-Dhellemmes S, Soto-Ares G, Dhellemmes P. Infantile subdural hematomas due to traffic accidents. Pediatr Neurosurg 2002;37:245-53

\section{Authors' reply}

As Professor Stephenson is aware from his own paediatric neurological practice, there are too many children who have been shaken and who have a constellation of characteristic neurological deficits. Over the years, infants and children who present with these features have come to be referred to as patients with 'shaken baby syndrome' (or shaken impact syndrome). In addition, much more has been learned about who the perpetrators are likely to be, possible prevention strategies, characteristics of lesions that are or are not typical for the syndrome, legal ramifications, long-term outcomes and so on. Professor Stephenson is also correct in pointing out that the specific pathogenesis remains the subject of ongoing investigation and attempts at modelling - a process of inquiry that has occurred for many other syndromes in the history of medicine. We could not agree more that belief with a religious passion has nothing to do with the relevance of the syndrome or our current understanding of it. There are many serious scientists and non-scientists who are making important contributions to our increasing understanding of the syndrome, who critically assess the assumptions underlying the concept and the diagnosis, and who will be presenting at the conference (for list of speakers see [www.dontshake.com]). Dr Jennian Geddes ${ }^{1}$, one of those listed by Professor Stephenson, was invited as a keynote speaker but declined the invitation.
While this conference will not solve all of the outstanding questions concerning the syndrome, it will be an opportunity for 'scientific enquiry and rational discourse'. We hope that Professor Stephenson and anyone else with an interest in the syndrome will take the opportunity to contribute.

\section{Marilyn Sandberg \\ Robert Minns}

\section{Ronald G Barr}

Planning Committee, European Conference on Shaken Baby Syndrome

\section{REFERENCE}

1 Geddes JF, Hackshaw AK, Vowles GH, Nickols CD, Whitwell HL. Neuropathology of inflicted head injury in children. I. Patterns of brain damage. Brain 2001;124:1290-8

\section{The purpose of RITA}

Mr Bache and his colleagues (December 2002, JRSM $M^{1}$ ) describe a broadened assessment for specialist registrars, built onto the mandatory record of in-training assessment (RITA). This account seems to me to typify the confusion between appraisal and assessment that lies at the root of our profession's consistent inability to self-regulate.

The RITA process was designed to be critical and judgmental, so that trainees could be assessed dispassionately, without their trainers present, irrespective of their career plans, the quality of their training or other mitigating factors - i.e. a pure judgment of their competence and hence of their competency to proceed to the next stage of training. (It was this which vindicated the removal of the registrar/senior registrar hurdle, so greatly lamented by seniors, when 'Calmanization' was introduced.) To confuse RITA with career guidance and evaluation of the training programme is to cloud its role in assessing competence, and thereby to encourage connivance between trainers, trainees and assessors if deficiencies are demonstrated - everyone explaining these away for their own purposes.

Some day we must wake up to the fact that, when doctors emerge poorly trained and inadequate, they are the product of just such a muddled method of assessment as the Liverpool authors propose.

\section{Peter Leaver}

28 Meynell Crescent,

London E9 7AS, UK

\section{REFERENCE}

1 Bache J, Brown J, Graham D. In-training assessment for specialist registrars: views of trainees and trainers in the Mersey Deanery. $J$ R Soc Med 2002;95:612-13 


\section{Supporting individuals with disabling multiple sclerosis}

The paper by Jeremy Gibson and Andrew Frank (December 2002, JRSM ${ }^{1}$ ) is a valuable contribution, bringing together understandings and advice which my wife, who has suffered from relapsing-remitting MS for 20 years, only gradually acquired despite being seen by many eminent neurologists in Britain, the United States and Italy. Though she received honest advice about the prognosis and essential untreatability of the condition, the many possible remedial actions and interventions discussed by Gibson and Frank were little considered and the most useful one which was provided - help from a very skilful neurophysiotherapist - was limited to six sessions because of NHS underfunding. We are fortunate to be able to pay for a parallel intervention in the form of Thai massage, a very active intervention producing major symptomatic improvement for 2-3 days.
Two additional points may be of general interest. First, in my wife's case high environmental temperatures produce major difficulty in walking and mental confusion, but these are instantly reversible by immersion in cold water. Second, I believe she might well have ended up needing a wheelchair had she not responded to phases of increased lower limb weakness and incoordination by furiously forcing herself to walk and so discovered that this restored sensation and coordination to their usual level. Phases of mental slowness are, it seems, similarly relieved by playing (and usually beating me at) chess.

\section{Anthony Ryle}

3 Goulton Road, London E5 8HA, UK

E-mail: rylecat@aol.com

\section{REFERENCE}

1 Gibson J, Frank A. Supporting individuals with disabling multiple sclerosis. J R Soc Med 2002;95:580-6

\section{May 19}

Thomas Trapham chirurgeon to the general of the parliamentary army was then actually created batch. of physic, while the said general Cromwell and the aforesaid officers were seated in their gowns in the doctor's seats-This person, who was the son of John Trapham of Maidstone in Kent, and had been licensed by the university to practice in chirurgery, an. 1633, did practise it in these parts for some years before the grand rebellion broke forth. Afterwards he turned tail for profit sake, practised in the parliament army, and became a bitter enemy to his majesty King Charles the first; to whose body after his decollation in the latterend of Jan. 1648 he put his hand to open and embalm, and when that was done, he sewed his head to his body; and that being done, also, he said to the company, then present, that "he had serw on the head of a goose". Afterwards he was chirurgeon to Oliver Cromwell at the fight at Worcester against king Charles II, was a great man among his party and got what he pleased. After his majesty's return, he returned to the fanatical town of Abingdon in Berks, practised there among the brethern, and dying an absolute bigot for the cause, in the latter end of Dec. 1683, was buried on the 20th of the same month in the presence of a great number of dissenters in the churchyard of St. Helen's there, close under one of the windows of that church.'

This passage is from Wood's Fasti. Wood identifies as son to this man one Thomas Trapham who qualified at another university. He travelled a great deal and spent some years in Jamaica. He returned to Oxford, was a proctor at Magdalen College and became a fellow of the College of Physicians. He wrote a book on the health of the inhabitants of Jamaica and later went back to Jamaica where he died in 1692 . 